\title{
ERRATUM \\ The Big Society in China: A Failed Experiment - ERRATUM
}

\section{Lei Jie and Alan Walker}

doi:10.1017/S147474641200036X, Published by Cambridge University Press.

The original version of this article (Lei \& Walker 2012) was published with author J. Lei's name incorrectly spelled. The correct spelling is Jie Lei. The error has been rectified in the online PDF and HTML copies.

\section{Reference}

Lei, J. and Walker, A. (2012) 'The Big Society in China: A Failed Experiment', Social Policy and Society, 12, 1, 17-30. 